\title{
Negative Tracheal Pressure During Neonatal Endotracheal Suction
}

\author{
NICHOLAS J. KIRALY, DAVID G. TINGAY, JOHN F. MILLS, COLIN J. MORLEY, AND BEVERLEY COPNELL
}

\begin{abstract}
Neonatal Research [N.J.K., D.G.T., J.F.M., C.J.M., B.C.], Murdoch Childrens Research Institute, Melbourne 3052, Australia; Faculty of Life and Social Sciences [N.J.K.], Swinburne University of Technology, Melbourne 3122, Australia; Department of Neonatology [D.G.T., J.F.M., C.J.M., B.C.], The Royal Children's Hospital, Melbourne 3052, Australia; Department of Paediatrics [D.G.T., C.J.M.], University
\end{abstract} of Melbourne, Melbourne 3052, Australia

\begin{abstract}
Endotracheal tube (ETT) suction is the most frequently performed invasive procedure in ventilated newborn infants and is associated with adverse effects related to negative tracheal pressure. We aimed to measure suction catheter gas flow and intratracheal pressure during ETT suction of a test lung and develop a mathematical model to predict tracheal pressure from catheter and ETT dimensions and applied pressure. Tracheal pressure and catheter flow were recorded during suction of ETT sizes $2.5-4.0 \mathrm{~mm}$ connected to a test lung with catheters 5-8 French Gauge and applied pressures of $80-200 \mathrm{~mm} \mathrm{Hg}$. The fraction of applied pressure transmitted to the trachea was calculated for each combination, and data fitted to three nonlinear models for analysis. Tracheal pressure was directly proportional to applied pressure $\left(r^{2}=0.82-0.99\right)$, and catheter flow fitted a turbulent flow model $\left(R^{2}=0.85-0.96\right)$. With each ETT, increasing catheter size resulted in greater catheter flow $(p<0.0001)$ and thus lower intratracheal pressure $(p<0.0001)$. The fraction of applied pressure transmitted to the trachea was accurately modeled using ETT and catheter dimensions $\left(R^{2}=0.98-0.99\right)$. Negative tracheal pressure during in vitro ETT suction is directly proportional to applied pressure. This relationship is determined by ETT and catheter dimensions. (Pediatr Res 64: 29-33, 2008)
\end{abstract}

$\mathrm{E}^{\mathrm{n}}$ ndotracheal tube (ETT) suction is the most frequently performed invasive procedure in ventilated newborn infants, and is important to maintain ETT patency and to prevent complications of secretion retention $(1,2)$. It is associated, however, with the potential for significant adverse effects including loss of lung volume, hypoxemia, and localized injury to the tracheobronchial tree (3-11). The cause of these adverse effects may be the exposure of the tracheobronchial tree to negative pressure $(5,12-14)$.

The chief determinants of intratracheal pressure during suction are thought to be applied suction pressure $\left(P_{\text {suction }}\right)$ and catheter size relative to ETT size $(14,15)$. The effect of suction on intratracheal pressure has been evaluated in vitro and in vivo for adult ETT and catheter sizes $(16,17)$, and in vivo studies have examined the effects of $P_{\text {suction }}$ and the relationship between ETT and suction catheter size on changes in oxygenation, respiratory

Received September 5, 2007; accepted February 7, 2008

Correspondence: Nicholas J. Kiraly, Neonatal Research, Murdoch Childrens Research Institute, Department of Neonatology, The Royal Children's Hospital, Flemington Road, Parkville, VIC 3052, Australia; e-mail: nicholas.kiraly@mcri.edu.au

This work was funded by National Health and Medical Research Council Medical Postgraduate Research Scholarship (to D.G.T.), National Health and Medical Research Council Medical program grant 384100 (to B.C.). mechanics, and cardiovascular dynamics $(5,18,19)$. Although larger catheters and higher $P_{\text {suction }}$ are found to generate lower intratracheal pressure than smaller catheters, the exact relationship between these variables has not been determined $(16,17,20)$.

In an in vitro lung model, intratracheal pressure was found to be inversely related to the cross-sectional area between the ETT and catheter for neonatal and pediatric ETT sizes during suction (using an applied pressure of $500 \mathrm{~mm} \mathrm{Hg}$ ) (20). However, this relationship was not mathematically defined. Rosen and Hillard (21) derived an equation to quantify intratracheal pressure in terms of ETT and suction catheter dimensions and applied suction pressure, but this equation did not account for the annular shape of the area between the ETT and catheter and has not been verified empirically (15).

The aim of this study was, in an in vitro lung model, to measure intratracheal pressure and catheter gas flow $\left(V_{\text {catheter }}^{\prime}\right)$ over the range of clinically used $P_{\text {suction }}$ for neonatal ETTs and suction catheters. In addition, we aimed to develop a mathematical model to define the relationship between the intratracheal pressure generated during suction and ETT size, suction catheter size, and $P_{\text {suction}}$.

\section{MATERIALS AND METHODS}

Ethical approval is not required for bench-top experiments in our institution. The study was performed using an infant test lung (Michigan Instruments 560li, Grand Rapids, MI) with a maximum volume of $150 \mathrm{~mL}$. An uncuffed ETT (Mallinckrodt, Rowville, Victoria, Australia) was connected to the "trachea" of the test lung with an ETT adaptor and sealed with silicon to prevent any leak. ETT leak was specifically excluded from the system as it occurs primarily during the higher tracheal pressure conditions of inspiration (22), and is thus unlikely to occur during the negative tracheal pressure conditions of suction. No resistance was added to the test lung and the compliance was set to $1 \mathrm{~mL} / \mathrm{cm} \mathrm{H}_{2} \mathrm{O}$.

For each suction episode, and with the system open to atmosphere, a catheter (Mallinckrodt, Rowville, Victoria, Australia) was inserted to the tip of the ETT and suction was applied for $6 \mathrm{~s}$, the typical duration of suction in our institutions, using a suction regulator (PM3000, Precision Medical Inc., Northampton, PA). The applied pressure of the regulator was set using a Timeter pressure measurement device (Timeter RT-200, St. Louis, MO) with the suction tubing occluded. Suction episodes were performed with sizes 5, 6 , 7 , and 8 French Gauge (FG) suction catheters (of length $30 \mathrm{~cm}$ ), and with suction pressure settings of $80,120,160$, and $200 \mathrm{~mm} \mathrm{Hg}$ in endotracheal

Abbreviations: $\boldsymbol{\Delta P}$, maximum intratracheal pressure change from atmospheric pressure; ETT, endotracheal tube; FG, French gauge; $\boldsymbol{P}_{\text {suction }}$, applied suction pressure; $\mathbf{T P}$, fraction of applied suction pressure transmitted to the trachea; $\boldsymbol{V}_{\text {catheter, }}^{\prime}$ suction catheter gas flow 
tubes of internal diameter 2.5, 3.0, 3.5, and $4.0 \mathrm{~mm}$. For each combination, six suction episodes were performed at 6-s intervals.

Intratracheal pressure was monitored at the distal end of the ETT with the Timeter pressure measurement device via low compliance pressure monitoring tubing (Saint-Gobain, Akron, OH). Preliminary testing confirmed that maximum intratracheal pressure change from atmospheric pressure $(\Delta P)$ was reached within 1 to $2 \mathrm{~s}$ of suction onset and did not vary thereafter; thus, this point was manually recorded during each suction episode as soon as a stable reading was obtained. $V_{\text {catheter }}^{\prime}$ was measured using a hot wire anemometer (Florian Respiration Monitor, Acutronic Medical Systems AG, Zug, Switzerland) incorporated into the circuit between the suction catheter and the suction regulator. The flow signal was digitally acquired at $200 \mathrm{~Hz}$ using a virtual instrument created in LabVIEW ${ }^{\mathrm{TM}} 6.0$ (National Instruments, Austin, TX).

Data analysis. For each catheter size, mean $( \pm \mathrm{SD}) \Delta P$ during suction was plotted against $P_{\text {suction }}$. Linear regressions were performed with zero offset according to the equation, $\Delta P=k \times P_{\text {suction }}$, as when $P_{\text {suction }}$ equals zero, tracheal pressure was defined as atmospheric pressure and hence $\Delta P$ equals zero.

Each flow tracing was reviewed manually by the same investigator. In all cases, the flow reached a steady state within $2 \mathrm{~s}$ of initiating suction. Some recordings contained artifact, hence to eliminate its effect $V_{\text {catheter }}^{\prime}$ was averaged over the final $3 \mathrm{~s}$ of each 6-s suction episode. For each catheter size, mean $( \pm \mathrm{SD}) V_{\text {catheter }}^{\prime}$ was plotted against $P_{\text {suction. }}$. In the presence of laminar flow, the gas flow in a pipe is directly proportional to the pressure drop across the pipe (23). Therefore, if $\Delta P$ is assumed to be directly proportional to $P_{\text {suction }}(21), V_{\text {catheter }}^{\prime}$ should be as well. To test this hypothesis, we performed linear regressions with no offset according to the equation, $V_{\text {catheter }}^{\prime}=k \times$ $P_{\text {suction }}$. However, if catheter gas flow is assumed to be turbulent, $V^{\prime}$ catheter is expected to be proportional to the square root of the pressure drop across the catheter (23). This model was tested by performing nonlinear regressions

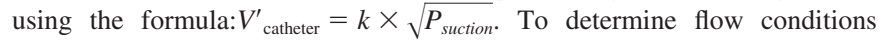
likely to exist within the catheter during typical conditions of ETT suction, the Reynolds number ${ }^{1}$ was calculated post hoc for all $V_{\text {catheter }}$ results.

Based on Rosen and Hillard's model, in which the pressure generated in the trachea is directly proportional to that generated by the suction regulator (15), the $\Delta P$ measurements were divided by corresponding $P_{\text {suction }}$ to produce the fraction of suction pressure transmitted to the trachea (TP). TP was plotted (for each suction catheter size) against cross-sectional area difference (Table 1) and data were compared with Rosen and Hillard's model (21) using Pearson's product-moment correlation coefficient. Data were also subjected to nonlinear regression analysis using a modified version of Rosen and Hillard's model and an exponential decay model. Details of the three models are given below.

Model 1. Rosen and Hillard's equation defines tracheal pressure as proportional to the ratio of the conductance (reciprocal of resistance) to gas flow of the catheter to the total conductance of gas flow between the suction apparatus and atmosphere (the sum of catheter conductance and ETT conductance with catheter inserted) (21):

$$
\Delta P=P_{\text {suction }} \frac{C^{4}}{C^{4}+\left(E^{2}-S^{2}\right)^{2}}
$$

where $C$ is the suction catheter internal diameter $(\mathrm{mm})$; $E$, ETT internal diameter $(\mathrm{mm}) ; S$, suction catheter external diameter $(\mathrm{mm})$. that;

This equation formulates that $\Delta P$ is directly proportional to $P_{\text {suction. }}$ Given

$$
A=(\pi / 4) \cdot\left(E^{2}-S^{2}\right)
$$

where $A$ is the cross-sectional area of the space between the ETT and suction catheter $\left(\mathrm{mm}^{2}\right)$.

Rosen and Hillard's equation can be rearranged to show the relationship between TP and $A$ :

$$
\mathrm{TP}=\frac{C^{4}}{C^{4}+16 / \pi^{2} \cdot A^{2}}
$$

where TP $=\Delta P / P_{\text {suction }}$.

Model 2. Rosen and Hillard's equation (21) was modified to account for the uncertain resistance of the space between the ETT and suction catheter and

${ }^{1}$ Formula used to calculate Reynolds number is $R e=\rho \times \nu \times d / \mu$, where $\rho$ is gas density $\left(\mathrm{kg} / \mathrm{m}^{3}\right), \nu$ is average gas velocity in the catheter $(\mathrm{m} / \mathrm{s}), d$ is catheter diameter $(\mathrm{m})$, and $\mu$ is dynamic gas viscosity (Pa·s) (23). This formula only holds true for Newtonian fluids, but given the pressure changes within our system are relatively small compared with absolute pressure, it is considered as a reasonable estimate for this application.
Table 1. ETT and suction catheter dimensions

\begin{tabular}{cccc}
\hline $\begin{array}{c}\text { ETT } \\
(\mathrm{mm} \mathrm{ID})\end{array}$ & $\begin{array}{c}\text { Suction catheter } \\
\text { FG (mm OD) }\end{array}$ & $\begin{array}{c}\text { Percentage } \\
\text { occlusion } \\
(\%)\end{array}$ & $\begin{array}{c}\text { Area } \\
\text { difference } \\
\left(\mathrm{mm}^{2}\right)\end{array}$ \\
\hline 2.5 & $5(1.7)$ & 44 & 2.7 \\
& $\mathbf{6}(\mathbf{2 . 0})$ & $\mathbf{6 4}$ & $\mathbf{1 . 8}$ \\
3.0 & $5(1.7)$ & 31 & 4.9 \\
& $6(2.0)$ & 44 & 3.9 \\
3.5 & $\mathbf{7}(\mathbf{2 . 3})$ & $\mathbf{6 0}$ & $\mathbf{2 . 8}$ \\
& $5(1.7)$ & 23 & 7.4 \\
& $6(2.0)$ & 33 & 6.5 \\
4.0 & $7(2.3)$ & 44 & 5.3 \\
& $\mathbf{8}(\mathbf{2 . 7})$ & $\mathbf{5 8}$ & $\mathbf{4 . 0}$ \\
& $5(1.7)$ & 17 & 10.4 \\
& $6(2.0)$ & 25 & 9.4 \\
& $7(2.3)$ & 34 & 8.3 \\
& $\mathbf{8}(\mathbf{2 . 7})$ & $\mathbf{4 4}$ & $\mathbf{7 . 0}$ \\
\hline
\end{tabular}

Percentage occlusion $=100 \times($ ETT internal cross sectional area/catheter external cross sectional area), Area difference $=$ ETT internal cross sectional area - suction catheter external cross sectional area, $\mathrm{mm}^{2}$ ), Bold denotes combinations recommended by Shann (25).

fitted to the data. The modified equation includes a constant $k$, the value of which was determined from nonlinear regression analysis:

$$
\mathrm{TP}=\frac{C^{4}}{C^{4}+k \cdot A^{2}}
$$

Model 3. Finally, an exponential decay model was fitted to the data, in which the constant, $k$, was determined by nonlinear regression:

$$
\mathrm{TP}=e^{-k A}
$$

Differences in $\Delta P$ and $V^{\prime}$ catheter for each increment in suction catheter size were analyzed using Student's $t$ tests, with a $p$ value of $<0.05$ considered statistically significant. All regression analyses were performed using the method of least squares and were analyzed using Pearson's product-moment correlation coefficient with the SigmaPlot 6.0 software package (SPSS Inc., Chicago, IL). Stata ${ }^{\mathrm{TM}}$ statistical software (Version 8.0, Stata Corporation, College Station, TX) was used for other statistical analysis. Values in text and figures are mean $\pm \mathrm{SD}$.

\section{RESULTS}

Intratracheal pressure. $\Delta P$ was found to be directly proportional to $P_{\text {suction }}$ for all combinations of ETT and suction catheters tested $\left(r^{2}=0.82-0.99\right.$; Fig. 1$)$. For every ETT size, the slope of the line increased with increasing catheter size. $\Delta P$ was significantly greater for any increase in catheter size for all combinations of ETT and $P_{\text {suction }}(p<0.0001)$.

Suction catheter gas flow rate. The linear, directly proportional relationship tested between $P_{\text {suction }}$ and $V_{\text {catheter }}^{\prime}$ was found to have poor correlation with the data $\left(r^{2}=0.00-0.61\right.$ for all combinations). However, when data were tested with nonlinear regression assuming turbulent flow, correlation was good $\left(R^{2}=0.85-0.96\right.$; Fig. 2$) . V_{\text {catheter }}^{\prime}$ was significantly greater for each incremental increase in catheter size for all ETT sizes over the range of $P_{\text {suction }}(p<0.0001)$.

Catheter flow conditions. Table 2 shows the calculated Reynolds numbers for the data set. Under the test conditions, turbulent flow tends to occur with catheter sizes 7 and 8 FG, regardless of the ETT with which they are used. The 6 FG catheter also tends to have turbulent flow, except with the smallest ETT $(2.5 \mathrm{~mm})$ and lowest $P_{\text {suction }}(80 \mathrm{~mm} \mathrm{Hg})$. The 5 FG catheter is likely to have laminar flow at lower $P_{\text {suction }}$ and turbulent flow at higher $P_{\text {suction}}$. 

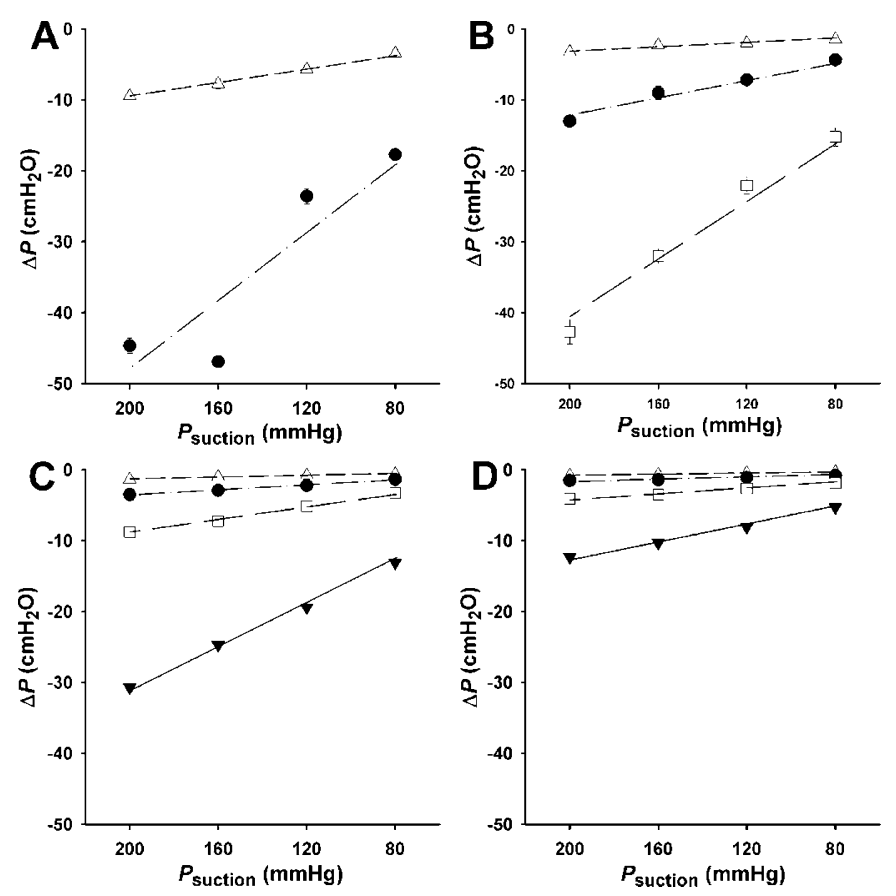

Figure 1. $A-D$, Tracheal pressure during suction $\left(\mathrm{cm} \mathrm{H}_{2} \mathrm{O}\right)$ plotted for catheter sizes $5 \mathrm{FG}(\triangle), 6 \mathrm{FG}(\bullet), 7 \mathrm{FG}(\square)$, and $8 \mathrm{FG}(\mathbf{\nabla})$ for an ETT internal diameter of $2.5 \mathrm{~mm}(A), 3.0 \mathrm{~mm}(B), 3.5 \mathrm{~mm}(C)$, and $4.0 \mathrm{~mm}(D)$ against the range of applied suction pressure. All data expressed as mean \pm SD. Lines represent linear regression for 5 FG (short dash), 6 FG (dash-dot), 7 FG (long dash), and 8 FG (solid line). Linear regression $r^{2}=0.82-0.99$.
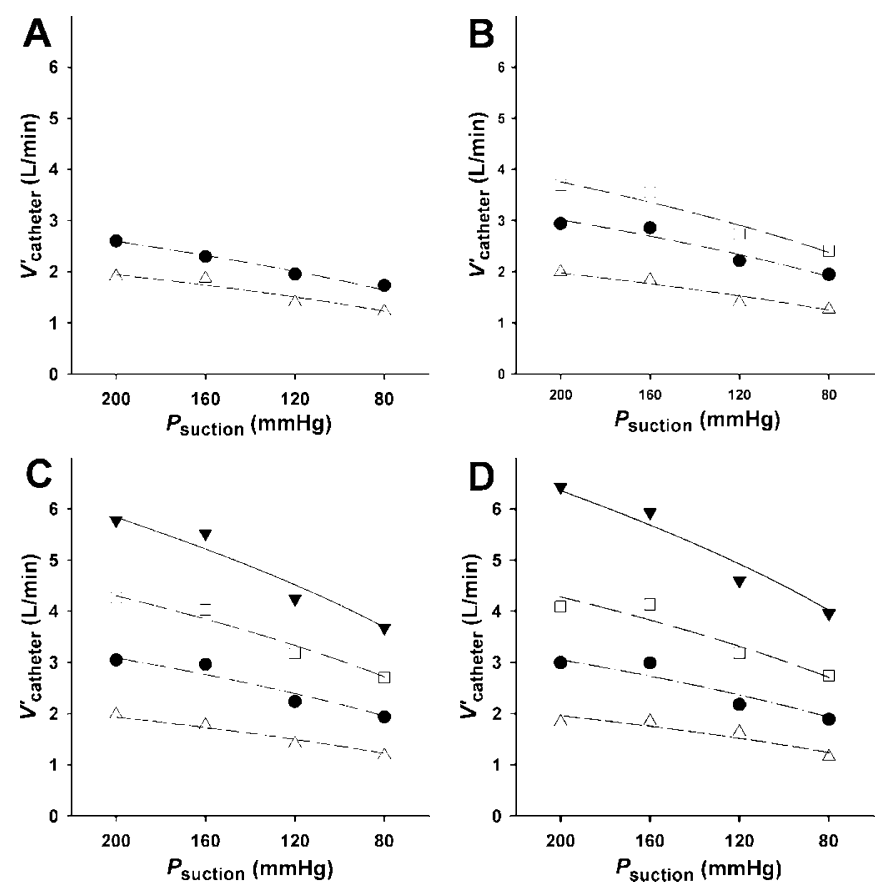

Figure 2. $A-D$, Catheter gas flow (L/min), averaged over last $3 \mathrm{~s}$ of suctioning, plotted against applied suction pressure. Data points correspond to suction with catheter sizes $5 \mathrm{FG}(\triangle), 6 \mathrm{FG}(\bullet), 7 \mathrm{FG}(\square)$, and 8 FG $(\boldsymbol{\nabla})$ with an ETT internal diameter of $2.5 \mathrm{~mm}(A), 3.0 \mathrm{~mm}(B), 3.5 \mathrm{~mm}(C)$, or $4.0 \mathrm{~mm}$ $(D)$. All data expressed as mean $\pm \mathrm{SD}$. Lines represent nonlinear regression $\left(V_{\text {catheter }}^{\prime}=k \times \sqrt{P_{\text {suction }}}\right.$ ) for $5 \mathrm{FG}$ (short dash), 6 FG (dash-dot), 7 FG (long dash), and 8 FG (solid line). Nonlinear regression $R^{2}=0.85-0.96$.
Tracheal pressure modeling. Correlations between the three models and the data are given in Table 3. Of all the models, the modified version of Rosen and Hillard's equation (Model 2) was found to fit the data most accurately $\left(R^{2}>0.98\right.$; Fig. 3$)$. The constant, $k$, generated by the regression analyses, was different for each catheter size (Table 3). For all sizes analyzed, the value of $k$ was greater than the constant in Model 1, and the 99\% CI did not include this value. This analysis was not performed for 8 FG catheters as only two ETT sizes were suctioned using this catheter size.

\section{DISCUSSION}

This study shows that large catheters and high suction pressures are associated with both high catheter gas flows and large negative tracheal pressures during ETT suction. Our data provide quantitative information about the negative pressure likely to be delivered to the trachea during ETT suctioning after a steady state has been reached.

The direct proportionality found between $\Delta P$ and $P_{\text {suction }}$ confirms the relationship proposed by Rosen and Hillard (21). Morrow et al. (20) reported a comparison between three different suction pressure settings of 200, 360, and $500 \mathrm{~mm}$ $\mathrm{Hg}$, but did not analyze the relationship further. In addition, they reported the effect of different size catheters for each ETT, showing considerable increases in $\Delta P$ when larger catheters are used, which agrees with our findings. Although guidelines recommend avoiding high suction pressures $(13,24)$, this study found that for a given ETT it is the combination of catheter size and suction pressure that determines the level of intratracheal pressure; thus, the two variables cannot be considered independently.

Rosen and Hillard developed a theoretical model (Model 1) where $\Delta P$ could be determined from the applied suction pressure, catheter internal diameter, catheter external diameter, and ETT internal diameter (21). As Rosen and Hillard concede, their model assumes laminar flow in all parts of the system, and that the resistance of the ETT (with catheter inserted) was equal to that of a pipe with equivalent crosssectional area (15). However, the annular shape of the ETT with catheter inserted can be expected to have greater resistance than the equivalent pipe; thus, we would expect the value of the constant in the rearranged Model 1 to be reduced. That the value of the constant, when calculated empirically in Model 2, is greater than Rosen and Hillard's theoretical value indicates that the resistance of the suction catheter may be greater than expected in comparison with the ETT (with catheter inserted).

The reason for this apparent increased resistance may be due to turbulent flow within the suction catheter. Indeed, the shape of the catheter flow data (Fig. 2) indicates a nonlinear and decreasing relationship between $P_{\text {suction }}$ and $V_{\text {catheter }}^{\prime}$, suggesting that flow is not laminar over the range of $P_{\text {suction }}$. This finding led us to calculate Reynolds number to estimate the flow conditions likely to exist within the catheter. The values obtained suggest changing flow conditions that depend on $P_{\text {suction }}$ and catheter size (Table 2), and that laminar flow is only likely with the combination of the smallest catheter (sizes 5 and 6 FG) and low suction pressures (80 and $120 \mathrm{~mm} \mathrm{Hg}$ ). 
Table 2. Reynolds number calculated from catheter flow data for each combination of suction catheter and ETT

\begin{tabular}{|c|c|c|c|c|c|}
\hline \multirow[b]{2}{*}{$\mathrm{ETT}(\mathrm{mm} \mathrm{ID})$} & \multirow{2}{*}{$\begin{array}{l}\text { Suction catheter } \\
\text { FG (mm OD) }\end{array}$} & \multicolumn{4}{|c|}{ Applied suction pressure } \\
\hline & & $80(\mathrm{~mm} \mathrm{Hg})$ & $120(\mathrm{~mm} \mathrm{Hg})$ & $160(\mathrm{~mm} \mathrm{Hg})$ & $200(\mathrm{~mm} \mathrm{Hg})$ \\
\hline \multirow[t]{2}{*}{2.5} & $5(1.7)$ & 1663 & 1901 & 2534 & 2592 \\
\hline & $6(2.0)$ & 1959 & 2208 & 2594 & 2938 \\
\hline \multirow[t]{3}{*}{3.0} & $5(1.7)$ & 1717 & 1900 & 2497 & 2708 \\
\hline & $6(2.0)$ & 2199 & 2505 & 3229 & 3325 \\
\hline & $7(2.3)$ & 2334 & 2658 & 3444 & 3575 \\
\hline \multirow[t]{4}{*}{3.5} & $5(1.7)$ & 1604 & 1918 & 2410 & 2690 \\
\hline & $6(2.0)$ & 2188 & 2531 & 3348 & 3446 \\
\hline & $7(2.3)$ & 2626 & 3079 & 3906 & 4136 \\
\hline & $8(2.7)$ & 2938 & 3386 & 4405 & 4613 \\
\hline \multirow[t]{4}{*}{4.0} & $5(1.7)$ & 1569 & 2224 & 2514 & 2492 \\
\hline & $6(2.0)$ & 2138 & 2463 & 3383 & 3388 \\
\hline & $7(2.3)$ & 2655 & 3090 & 4005 & 3965 \\
\hline & $8(2.7)$ & 3159 & 3671 & 4733 & 5130 \\
\hline
\end{tabular}

Reynolds numbers less than the critical value of 2000 are considered to result in laminar flow and greater than 4000 to indicate turbulent flow. Numbers between 2000 and 4000 indicate conditions where a minor disturbance is likely to revert flow to turbulent (23). Because the suction catheter is not perfectly straight and other imperfections exist, in this experiment, Reynolds numbers above 2000 (in bold) are likely to indicate turbulent flow.

Table 3. Mathematical modeling of fraction of applied pressure transmitted to the trachea (TP) vs. cross-sectional area difference between the ETT and suction catheter (A)

\begin{tabular}{|c|c|c|c|c|c|}
\hline \multirow{2}{*}{$\begin{array}{l}\text { Suction catheter } \\
\text { FG (mm OD) }\end{array}$} & \multirow{2}{*}{$\mathrm{TP}=\frac{\text { Model 1 }}{C^{4}} \frac{C^{4}+16 / \pi^{2} \cdot A^{2}}{R^{2}}$} & \multicolumn{2}{|c|}{$\begin{array}{c}\text { Model 2 } \\
\mathrm{TP}=\frac{C^{4}}{C^{4}+k \cdot A^{2}}\end{array}$} & \multicolumn{2}{|c|}{$\begin{array}{c}\text { Model } 3 \\
\mathrm{TP}=e^{-\mathrm{k} \mathbb{A}}\end{array}$} \\
\hline & & $k(99 \% \mathrm{CI})$ & $R^{2}$ & $k(99 \% \mathrm{CI})$ & $R^{2}$ \\
\hline $5(1.7)$ & 0.00 & $3.768(3.66-3.88)$ & 0.99 & $1.226(1.16-1.29)$ & 0.80 \\
\hline $6(2.0)$ & 0.12 & $3.194(3.07-3.32)$ & 0.99 & $0.977(0.93-1.02)$ & 0.96 \\
\hline $7(2.3)$ & 0.10 & $3.009(2.84-3.17)$ & 0.98 & $0.685(0.66-0.71)$ & 0.98 \\
\hline
\end{tabular}

$k=$ constant calculated by nonlinear regression, $R^{2}=$ regression correlation coefficient

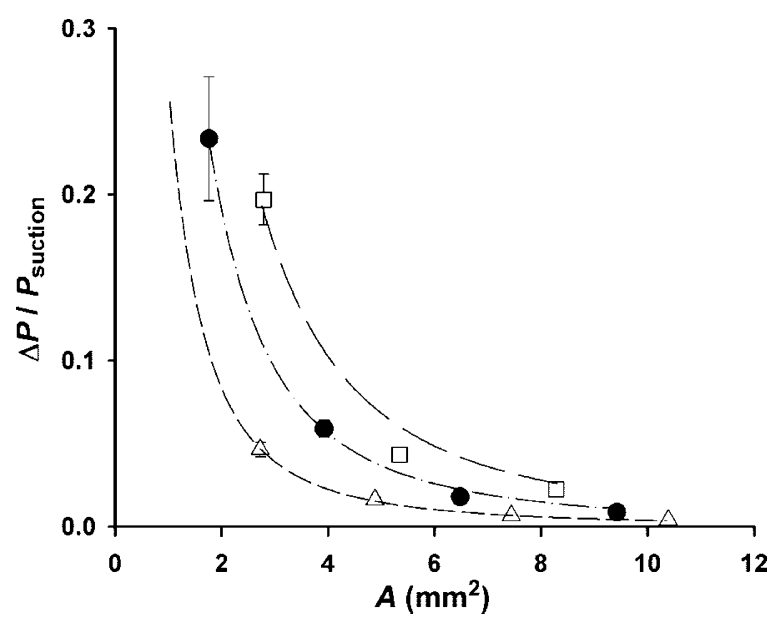

Figure 3. Fraction of applied pressure transmitted to the trachea plotted against cross-sectional area difference between the ETT and suction catheter. Curves represent suction catheters $5 \mathrm{FG}(\triangle), 6 \mathrm{FG}(\bullet)$, and $7 \mathrm{FG}(\square)$ and each data point represents use with a specific ETT size (see Table 1). All data expressed as mean $\pm \mathrm{SD}$. Nonlinear regressions are of the form, $\mathrm{TP}=C^{4} /\left(C^{4}+k \cdot A^{2}\right)$ (model 2, see METHODS for details). Lines represent regression for $5 \mathrm{FG}$ (short dash), 6 FG (dash-dot), and 7 FG (long dash). Nonlinear regression $R^{2}=0.98-0.99$. Regression data for $5 \mathrm{FG}$ are extrapolated to $1.0 \mathrm{~mm}^{2}$ to represent use with a 2.0 ETT.

We found a more accurate fit when using the turbulent flow model than a laminar model to compare $P_{\text {suction }}$ with $V^{\prime}{ }_{\text {catheter }}$. Although this model is not correct for all conditions, it is a reasonable estimate of the data within the ranges of $P_{\text {suction }}$ and catheter size tested. Reynolds number calculations are a more difficult prospect for the ETT component of the circuit, but the increased surface area within the system when compared with the equivalent pipe is likely to increase the probability of turbulent flow. However, the cross-sectional area is greater in this part of the circuit than in the catheter for all combinations tested; therefore, average gas velocity and, thus, Reynolds number are reduced. Again, that the experimental values of TP are less than Rosen and Hillard's model predicts indicates that turbulent flow is more prevalent within the catheter than within the ETT during suction. This analysis serves primarily to explain the observed data, and also indicates that if calculations were based on Rosen and Hillard's model, the magnitude of intratracheal pressure drop during suction would be overestimated.

This study has clinical implications. During suction of ETT sizes 2.5-4.0 ID, any increase in catheter size results in significantly greater $\Delta P$ and $V_{\text {catheter }}^{\prime}$ In some instances, the combination of a smaller catheter and higher $P_{\text {suction }}$ results in lower $\Delta P$, which may be less traumatic to the tracheobronchial tree while maintaining $V^{\prime}{ }_{\text {catheter }}$. For example, with a $3.5 \mathrm{~mm}$ ID ETT, a 7 FG catheter used with a relatively high $P_{\text {suction }}$ $(200 \mathrm{~mm} \mathrm{Hg}$ ) may be preferable to an $8 \mathrm{FG}$ catheter with low $P_{\text {suction }}$ as is often recommended (24,25). The adverse effects of negative airway pressure have been described, but acceptable levels of $\Delta P$ remain to be determined. In an animal study, using a higher suction pressure resulted in greater tracheobronchial trauma than a lower pressure (5), although the exact value of intratracheal pressure was unknown. Generation of negative airway pressure is also assumed to lead to loss of lung volume 
$(12,15)$; the relationship between tracheal pressure and volume change will be affected by respiratory mechanics and cannot be extrapolated from our data.

The results of our study are largely independent of patient conditions such as lung volume and respiratory mechanics, although these factors will influence the clinical effects of the tracheal pressure that is generated, as indicated earlier. In addition, such factors may affect the rate at which the pressure is reached, and suction may cease before the steady state being achieved depending on the duration of suction. Airway resistance, because of airway geometry or the presence of secretions, may also slow the movement of gas out of the lungs, and thus alter the rate of delivery of negative pressure to the distal airways.

Suction effectiveness must also be considered when choosing catheter sizes and suction pressures. Little is known of the impact of these variables on secretion removal. This study mimicked an open suction technique, which is widely used in clinical practice $(19,26)$, but further studies are required to determine the effect of various catheter size and suction pressure combinations using a closed suction technique.

A limitation of this experiment is the exclusion of mucus from the system. As the primary indication for suction is clearance of secretions in the airway, in clinical practice the inside of the ETT and airways are likely to be coated with mucus. If the secretions cause a narrowing of the ETT, the value of $\Delta P$ found in this experiment is likely to be increased as the area difference between ETT and suction catheter is reduced. However, if secretions partially or completely occlude the suction catheter, both $V_{\text {catheter }}^{\prime}$ and $\Delta P$ may be reduced (20). In clinical practice, the exact amount and consistency of secretions can never be known, and it is impossible to test every potential scenario in a bench test. The scenario tested in this experiment, namely suction in the absence of secretions, is likely to occur in practice (19), particularly if multiple passes of the catheter are made.

The bench top nature of this experiment specifically excludes effects from patient effort or physiologic variation during suctioning. A large spontaneous breath during suction may further reduce $\Delta P$ during the procedure, but forced expiration may increase $\Delta P$ in the presence of the obstruction by the suction catheter. Thus, we estimated that the recorded $\Delta P$ represents the average that would be expected, even during spontaneous breathing and the corresponding dynamic changes in lung volume. Although these effects may alter the variations in $\Delta P, V^{\prime}{ }_{\text {catheter }}$, and suction efficacy over the course of a suctioning episode, we believe that the results shown here provide a good indication of the effect of catheter size and $P_{\text {suction }}$ during ETT suctioning.

In conclusion, in the in vitro model, negative tracheal pressure during ETT suction is directly proportional to applied pressure, and has a nonlinear relation to suction catheter and ETT dimensions. Gas flow in the suction catheter is likely to be turbulent with most catheter and ETT combinations and this flow condition alters the predicted value of tracheal pressure.

Acknowledgments. The authors thank Dr. Ingo Bojak (Swinburne University of Technology) for reviewing this manuscript.

\section{REFERENCES}

1. Landa JF, Kwoka MA, Chapman GA, Brito M, Sackner MA 1980 Effects of suctioning on mucociliary transport. Chest 77:202-207

2. Guglielminotti J, Desmonts JM, Dureuil B 1998 Effects of tracheal suctioning on respiratory resistances in mechanically ventilated patients. Chest 113:1335-1338

3. Brandstater B, Muallem M 1969 Atelectasis following tracheal suction in infants. Anesthesiology 31:468-473

4. Simbruner G, Coradello H, Fodor M, Havelec L, Lubec G, Pollak A 1981 Effect of tracheal suction on oxygenation, circulation, and lung mechanics in newborn infants. Arch Dis Child 56:326-330

5. Kuzenski BM 1978 Effect of negative pressure on tracheobronchial trauma. Nurs Res 27:260-263

6. Loubser MD, Mahoney PJ, Milligan DW 1989 Hazards of routine endotracheal suction in the neonatal unit. Lancet 1:1444-1445

7. Turner BS, Loan LA 2000 Tracheobronchial trauma associated with airway management in neonates. AACN Clin Issues 11:283-299

8. Tingay DG, Copnell B, Mills JF, Morley CJ, Dargaville PA 2007 Effects of open endotracheal suction on lung volume in infants receiving HFOV. Intensive Care Med 33:689-693

9. Brodsky L, Reidy M, Stanievich JF 1987 The effects of suctioning techniques on the distal tracheal mucosa in intubated low birth weight infants. Int J Pediatr Otorhinolaryngol 14:1-14

10. Choong K, Chatrkaw P, Frndova H, Cox PN 2003 Comparison of loss in lung volume with open versus in-line catheter endotracheal suctioning. Pediatr Crit Care Med 4:69-73

11. Kerem E, Yatsiv I, Goitein KJ 1990 Effect of endotracheal suctioning on arterial blood gases in children. Intensive Care Med 16:95-99

12. Hodge D 1991 Endotracheal suctioning and the infant: a nursing care protocol to decrease complications. Neonatal Netw 9:7-15

13. Young CS 1984 Recommended guide lines for suction. Physiotherapy 70:106-108

14. Boothroyd AE, Murthy BV, Darbyshire A, Petros AJ 1996 Endotracheal suctioning causes right upper lobe collapse in intubated children. Acta Paediatr 85:1422-1425

15. Rosen M, Hillard EK 1962 The effects of negative pressure during tracheal suction. Anesth Analg 41:50-57

16. Lindgren S, Almgren B, Hogman M, Lethvall S, Houltz E, Lundin S, Stenqvist O 2004 Effectiveness and side effects of closed and open suctioning: an experimental evaluation. Intensive Care Med 30:1630-1637

17. Stenqvist O, Lindgren S, Karason S, Sondergaard S, Lundin S 2001 Warning! suctioning. A lung model evaluation of closed suctioning systems. Acta Anaesthesiol Scand 45:167-172

18. Singh NC, Kissoon N, Frewen T, Tiffin N 1991 Physiological responses to endotracheal and oral suctioning in paediatric patients: the influence of endotracheal tube sizes and suction pressures. Clin Intensive Care 2:345-350

19. Morrow B, Futter M, Argent A 2006 Effect of endotracheal suction on lung dynamics in mechanically-ventilated paediatric patients. Aust J Physiother 52:121126

20. Morrow BM, Futter MJ, Argent AC 2004 Endotracheal suctioning: from principles to practice. Intensive Care Med 30:1167-1174

21. Rosen M, Hillard EK 1960 The use of suction in clinical medicine. Br J Anaesth 32:486-504

22. Kondo T, Matsumoto I, Lanteri CJ, Sly PD 1997 Respiratory mechanics during mechanical ventilation: a model study on the effects of leak around a tracheal tube. Pediatr Pulmonol 24:423-428

23. Douglas JF, Gasiorek JM, Swaffield JA, Jack LB 2005 Fluid Mechanics. Prentice Hall, Essex, UK, pp 101-102

24. Goldsmith JP, Karotkin EH 1996 Assisted Ventilation of the Neonate. W.B. Saunders Company, Philadelphia, pp 116-117

25. Shann F 2005 Drug Doses. Collective Pty Ltd, Melbourne, pp i

26. Gonzalez-Cabello H, Furuya ME, Vargas MH, Tudon H, Garduno J, GonzalezAyala J 2005 Evaluation of antihypoxemic maneuvers before tracheal aspiration in mechanically ventilated newborns. Pediatr Pulmonol 39:46-50 